can protect against the virus and is of use in treating cases of the disease and also in making a vaccinating mixture with live virus, which has the practical advantage of needing only one dose instead of two. These immunological reactions also make it possible to identify the disease with far greater certainty, and the new methods of prevention are available for ferrets, silver foxes, fitches, thinks, etc., in which it has been found to occur.

\section{Halley Stewart Laboratories of bhysical Research}

IT seems to be a remarkable coincidence that during the past century much of the research by the professors of physics in King's College, London, has been directly applicable to distant communication. Wheatstone appears to have been the pioneer and is known to all by his ingenuity and his discoveries which led to the invention of telegraphy. Maxwell, whose genius covered a wide range of study, is best known for work which is the theoretical basis of wireless transmission to-day. Richardson's work on the emission of electrons from hot bodies is applied in every wireless set. To-day, Appleton is in the forefront of the workers who are studying conditions in the upper atmosphere which control wireless transmission. But however comfortably his predecessors may have worked in the friendly atmosphere of the College, the conditions have so changed in the surroundings that Prof. Appleton finds himself obliged to work in a continuous electromagnetic storm-an atmosphere unsuitable to the character of the work in which he, his colleagues and his students are engaged. The work is already past the stage of a direct study of the conditions of wireless communication and has become of great importance in the study of the structure and nature of the upper atmosphere. By the refraction of wireless waves within the upper atmosphere, information is being obtained about the distribution of ionised regions. Thus hypotheses already applied in other branches of geophysical work come within the reach of direct experimental investigation.

The problems which Prof. Appleton is attacking are of great complexity and it is clearly desirable not to add to the difficulty by working in a region so disturbed electrically as the Strand. Thus the generosity of the Halley Stewart Trust in providing new laboratories at Chesterford Gardens, Hampstead, is very opportune and is welcomed by the College and especially by the Physics Department. The work now in progress involves observations of a protracted nature-often over twenty-four hours-so that the convenience of a special laboratory with the director of research housed on the spot cannot be overestimated. The other branch of research to be undertaken in the building is concerned with the physical problems arising in the medical application of radium. This work is proceeding apace in London and one of its objects is to introduce scientific accuracy into the therapeutic use of radioactive sub. stances. Already a number of students working under the direction of Dr. H. T. Flint are engaged in King's College and in Westminster Hospital
Annexe on urgent problems in this branch of physics. The proximity of the new laboratories to Westminster Hospital Annexe will still further promote the close co-operation of the work in the two places.

\section{Protein Swelling and Allied Phenomena}

A Conference devoted to the subject of protein swelling, held under the auspices of the British Section of the International Society of Leather Trades Chemists, was held on December 1 at the Leathersellers' Hall, London, E.C.3. The introductory address was given by Prof. F. G. Donnan on the theory of membrane equilibria and the osmotic pressure of protein gels, in the course of which points connected with the Procter-Wilson theory of osmotic swelling were touched upon, and attention directed to the difficulty of applying this theory quantitatively to close-packed micellar systems such as hide. $\mathrm{Mr}$ G. S. Adair dealt with the osmotic pressure of the proteins, and described the assistance afforded by analysing such pressure into two partial pressures, one due to the protein ions and the other to the unequal distribution of ions. Dr. H. Phillips discussed the interaction of gelatin with acids and alkalis from the points of view of the electronic theory of valency and Bjerrum's Zwitterion constitution of amino acids. Mr. F. C. Thompson explained the two types of salt effect on the swelling of gelatin, one, an osmotic repressive effect on acid or alkali swollen gelatin, and the other a lyotrope effect on neutral non-ionised gelatin. Dr. R. H. Marriott, in his paper on swelling in alkaline solutions, put forward his views on the mechanism of the fixation of calcium by collagen, and the influence of the chemical constitution of keratin on its resistance to osmotic swelling.

THe more practical aspects of swelling and its bearing on leather manufacture were summarised by Dr. C. H. Spiers, who considers that plumping of hides is associated with a twisting and folding of the polypeptide chains in the crystallites of the fibrils. Dr. Dorothy Jordan Lloyd put forward explanations for the observed reductions in swelling power of proteins with increasing compactness of molecular organisation. The structure of wool keratin and its relation to swelling phenomena, was the subject of Dr. J. B. Speakman's paper, while the last paper was given by Mr. W. R. Atkin, on swelling in weak acids, in which it was pointed out that a careful consideration of Kuhn's work shows that the maximum swelling of gelatin in weak acid is at an external equilibrium of $p \mathbf{H ~} 2 \cdot 4$ in agreement with the earlier work of Procter.

\section{Cinematograph Films of Cyclic Phenomena}

Messrs. Dance-Kaufmann, 18 Upper Stanhope Street, Liverpool, have produced some useful technical films which aim at the representation, by means of moving pictures, of phenomena which are cyclic, or may be considered so, for the purposes of exhibition. The operation of a diagram for the composition of rotating vectors; the summation of three alternating fields displaced in space and time; 